rate $76.9 \%$; males $74.2 \%$; mean age 46.0 yrs (SD 12.6), range 18-75 yrs; mean symptom duration 19.8 yrs) and 6 months. Self-reported AS and general health transition at 6 months were the criteria used to assess validity and responsiveness. The relationship between changes in instrument scores and responses to transition items was assessed for a linear trend.

Results Significant correlations between mean change in instrument scores and both forms of transition question supports the longitudinal validity of all instruments $(p<0.001)$ : the largest levels of change were found for the PGI-AS and the Bath AS Disease Activity Index (BASDAI), both demonstrating a stronger relationship with general transition. The modified standardised response mean (MSRM) was used to assess responsiveness (Table 1). The Body Chart, a measure of AS specific pain, had a moderate relationship with AS transition only (better -0.44 , worse 0.51 ), which may support the importance of specific pain evaluation.

Conclusion Although certain domains may not be expected to change over 6-months, this period reflects normal practice in AS evaluation in many rheumatology centres. The responsiveness of the PGI-AS and BASDAI may make them suitable for routine monitoring where management may result in small but important changes in health related quality of life.

\begin{tabular}{|c|c|c|c|c|}
\hline & $\begin{array}{l}\text { AS } \\
\text { transition - } \\
\text { MSRM } \\
\text { Better ( } \mathrm{n}= \\
56 \text { ) }\end{array}$ & $\begin{array}{l}\text { AS } \\
\text { transition - } \\
\text { MSRM } \\
\text { Worse ( } n= \\
73)\end{array}$ & $\begin{array}{l}\text { General } \\
\text { transition - } \\
\text { MSRM } \\
\text { Better ( } n=51)\end{array}$ & $\begin{array}{l}\text { General } \\
\text { transition - } \\
\text { MSRM } \\
\text { Worse }(n=62)\end{array}$ \\
\hline $\begin{array}{l}\text { AS Quality of Life } \\
\text { (ASQoL) }\end{array}$ & -0.29 & 0.35 & -0.55 & 0.26 \\
\hline BASDAI & -0.60 & 0.22 & -0.67 & 0.43 \\
\hline $\begin{array}{l}\text { Revised Leeds } \\
\text { Disability (RLDQ) }\end{array}$ & -0.32 & 0.28 & -0.37 & 0.34 \\
\hline $\begin{array}{l}\text { PGI-AS (informed/ } \\
\text { open) }\end{array}$ & $0.42(n=20)$ & $\begin{array}{l}-0.48(\mathrm{n}= \\
21)\end{array}$ & $0.74(n=25)$ & $-0.75(n=18)$ \\
\hline
\end{tabular}

\section{HP0035 ASSOCIATION BETWEEN TESS FUNCTIONAL QUESTIONNAIRE AND TIMED TESTS OF FUNCTION}

${ }^{1} \mathrm{KL}$ Barker, ${ }^{2} \mathrm{SE}$ Lamb, ${ }^{3} \mathrm{AH}$ Simpson. ${ }^{1}$ Physiotherapy Research Unit, Nuffield Orthopaedic Centre NHS Trust, Oxford; ${ }^{2}$ School of Health and Social Sciences, Coventry University, Coventry; ${ }^{3}$ Department of Orthopaedic Surgery, University of Edinburgh, Edinburgh, UK

\subsection{6/annrheumdis-2001.1269}

Background It is important to evaluate the functional result of any orthopaedic intervention. This is commonly achieved by completing tests which evaluate function in a controlled environment under a specific set of conditions, allowing objective measures to be gathered. Alternatively patient-reported assessments may be used, which reveal the limitations that the patients experience when carrying out everyday activities in their own environment. This study investigated the association between these two methods.

Method 40 adult patients undergoing lower limb reconstruction surgery completed the Toronto Extremity Salvage Score (TESS) pre-operatively and at 6,12 and 24 months post surgery. TESS evaluates a single domain, physical disability, based on patients' reports of their function. It is applicable to a heterogeneous population being sensitive to change across a range of levels of disability. ${ }^{1}$ They also performed 3 timed tests of stair climbing, sit-to-stand and walking.

Results Within subjects changes were analysed using the Wicoxon matched-pairs test and associations between variables by a Spearman's Rank Correlation Coefficient.

Subjects, on average, improved on all of the functional measures, with significant improvements from the baseline score at 12 and 24 months $(P<0.001)$. Changes at 6 months were not significant. There was a poor correlation between TESS and the timed function tests. To explore this further the association between specific questions in TESS and the objective performance tests were tested. This showed significant correlations between walking speed and the question about walking indoors (0.53, $\mathrm{P}<0.003)$, between stair climbing and the question about going upstairs $(0.64, \mathrm{P}<0.001)$ and downstairs $(0.42, \mathrm{P}$ $<0.025)$ and sit-to-stand and the question about getting out of a chair $(0.41, \mathrm{P}<0.03)$.

Conclusions The association between the self-reported and observed outcome measures was not as strong as may have been expected when both purport to measure the same dimension of physical function. One explanation for this may be that the observed outcomes were all timed activities and patients' satisfaction with their functional abilities may not be related to time. Whilst timed tests may be reliable tests of function, they may not be as valid or useful a measure as patient-reported measures.

\section{REFERENCE}

1 Davis AM, Bell RS, Badley EM, et al. Evaluating functional outcome in patients with lower extremity sarcoma. Clin Orthop Relat Res. 1999;358:90-100

\section{SP0169 NEW APPROACH TO THE CARE OF RHEUMATIC PATIENTS WITHIN THE PROJECT "PATIENT PARTNERS"}

M Dobesova. Out-Patients Department for Rheumatic Patients, Hospital in Bruntal, Bruntal, Czech Republic

10.1136/annrheumdis-2001.1270

New approaches to the care of rheumatic patients within the Project "Patients Partner". An important component of the care of patients with a chronic rheumatic disease is a complex care and an individual approach. Rheumatism is generally thought of as a disease of elderly persons, although certain types of rheumatism attack also younger age groups. There are various topics that I feel deserve to be given attention to:

- Communication and information - the patient should learn communication skills and should receive a maximum of information about his disease and its treatment.

- Complex care and the importance of teamwork. Of importance is a good collaboration among the various specialists. The role of the nurse in providing complex care is indispensable.

- Establishment of national and international organisations of rheumatic patients - a good opportunity for meeting other patients, exchanging experience, giving advice about how to cope with pain. A good example is the Revma League in Prague and its branch at Bruntal.

- Social problems - equal rights for healthy and disabled persons (Public transport, abolishment of legal discrimination etc.). 